\title{
Analysis of the Quadrupole Coupling Constants and Mössbauer Iso- meric Shifts in Halogen Compounds Within the Gaussian98 Code
}

\author{
O. Kh. Poleshchuk, J. N. Latosińska, and B. Nogaj \\ Institute of Physics, Adam Mickiewicz University, Umultowska 85, 61-614 Poznań, Poland \\ Reprint requests to Dr. J. N. L.; Fax: +48-61-8257758; E-mail: jolanala@amu.edu.pl \\ Z. Naturforsch. 55 a, 271-275 (2000); received September 11, 1999 \\ Presented at the XVth International Symposium on Nuclear Quadrupole Interactions, \\ Leipzig, Germany, July 25 - 30, 1999.
}

\begin{abstract}
A comparison of the experimental and calculated nuclear quadrupole coupling constants of diatomic halogen, interhalogen, trihalide ions and complexes of pyridine is a good test of reliability of semiempirical and non-empirical theories as well as their usefulness in the interpretation of quadrupole coupling data from the qualitative and quantitative point of view. Therefore, a practical way of gaining insight into the bonding properties and electronic structure of such systems consists of combining semiempirical MO calculations with experimental data to derive reliable information. In the present work we report the results of ab initio studies of several iodine containing molecules and ions using the calculated NQCC as a test of the quality of the wavefunctions. To demonstrate the quality of our calculations, we compare the calculated halogen-halogen bond length and QCC with the corresponding experimental values for the compounds studied. With a few exceptions, the overall agreement with experiment is most satisfactory. The results on dipole moments and energy levels are also in a good agreement with the experimental data, however these quantities were measured only in the few cases.
\end{abstract}

Key words: DFT; QCC; Isomeric Mössbauer Shifts; Halogen Compounds.

\section{Introduction}

The nuclear quadrupole coupling constants (QCC) of diatomic halogenides, their ions and interhalogen compounds are well known [1]. A good test of various semiempirical as well as nonempirical methods could be the quality of reproduction of NQR parameters. It should be pointed out that all halogen atoms have quadrupole moments either in the ground or in the excited states (in the case of fluorine atom) and therefore could be very useful for testing different methods of calculations.

Usually such an analysis is performed on the basis of the Townes-Dailey approximation [2], which allows a comparison of quadrupole coupling constant (QCC) obtained from experiment and calculated on the basis of density matrix values.

The QCC of halogen atoms have recently been calculated by ab initio methods within the density functional theory (DFT), in particular the $\mathrm{X} \alpha$ method
[3 - 6]. However, the latter method is not really a nonempirical one, because it involves an empirical parameter $\alpha$ which varies in the range from 0,6 up to 1 . The second group of methods includes: LAPW [7, 8], LMTO [9, 10], KKR [11] and PAW [12], which are the so-called solid state methods. They allow a more precise description of wave functions close to the nuclei and have recently been applied to the calculations of QCC of halogen atoms. The limitation of these methods is that they demand the not always existing knowledge of the molecular packing in a crystal.

In our earlier papers we calculated the QCC by $\mathrm{ab}$ initio methods using HONDO and GAUSSIAN94 packages $[13,14]$ for heavy nuclei, such as iodine, tin and antimony in some complexes containing these elements.

Direct calculations of the electric field gradient at iodine, tin and antimony atoms have shown that the use of a pseudopotential for these atoms does not lead to QCC values reliable enough. The results obtained for chlorine and nitrogen atoms in the extended basis 
set i.e. 6-311G*, are in a good agreement with experimental values.

The aim of this paper is to check the usefulness of the DFT methods for QCC and isomeric shift calculations on halogen atoms.

\section{Calculation Details}

The QCC values of halogen atoms were calculated within the density functional theory and using new hybrid functionals, such as B3P86, B3PW91, MPW1PW91, BH, HLYP, and B3LYP. The main aim was to obtain reliable values of the electronic density distribution on atoms as well as the electric field gradients at the nuclei. The full optimisation of geometry was achieved within the GAUSSIAN98 program [15] run on a PC or Cray (PCSS, Domain).

All the functionals used contained local and nonlocal exchange and correlation terms, and differed in the form of the correlation functional. One of them, BLYP, contains a correlation functional introduced by Lee [16] (which includes both local and non-local terms), while the BP86 functional contains the local and non-local terms proposed by Perdew [17]. The other two approaches are the so-called hybrid methods since they incorporate some degree of exact Hartree-Fock exchange. The Becke hybrid functional (B3PW91) [18] can be expressed in the form

$$
\begin{aligned}
E_{\mathrm{XC}}= & (1-A) * E_{\mathrm{X}}^{\mathrm{Slater}}+A * E_{\mathrm{X}}^{H F}+B * E_{\mathrm{X}}^{\text {Becke }} \\
& +E_{\mathrm{C}}^{\mathrm{LSD}}+C * E_{\mathrm{C}}^{\mathrm{PW} 91}
\end{aligned}
$$

where $E_{\mathrm{X}}^{\mathrm{HF}}$ is the Hartree-Fock exchange, $E_{\mathrm{X}}^{\text {Slater }}$ the local exchange functional taken after Slater, $E_{\mathrm{X}}^{\text {Becke }}$ the gradient correction exchange taken after Becke [18], $E_{\mathrm{C}}^{\mathrm{LSD}}$ the local spin density (LCD) local correlation functional [19], and $E_{\mathrm{C}}^{\mathrm{PW} 91}$ the 1991 gradient functional of Perdew and Wang [19]. The coefficients $A, B$, and $C$ were determined using accurate experimental data [20] (56 atomisation energies, 42 ionisation potentials and 8 proton affinities). The hybrid B3LYP functional, proposed by Stephens et al. [21], replaces $\left\{E_{\mathrm{C}}{ }^{\mathrm{LSD}}+C * E_{\mathrm{C}}{ }^{\mathrm{PW}}{ }^{\mathrm{S} 1}\right\}$ by $C * E_{\mathrm{C}}{ }^{\mathrm{LYP}}+$ $(1-C) E_{\mathrm{C}}{ }^{\mathrm{VWN}}$, where $E_{\mathrm{C}}{ }^{\mathrm{LYP}}$ is the correlation functional of Lee et al. [16], and $E_{C}{ }^{V W N}$ is the total correlation functional of Vosko et al. [22]. Note that the $(1-C) E_{\mathrm{C}}{ }^{\mathrm{VWN}}$ term is added because $E_{\mathrm{C}}{ }^{\mathrm{LYP}}$ contains both local and non-local terms.
Table 1. The experimental and calculated QCC $(\mathrm{MHz})$ for halogen atoms with the application of the different functional in $3-21 \mathrm{G}^{*}$ basis set.

\begin{tabular}{llllllllll}
\hline Mol. & Nuclei & HF & MP2 & B3 & B3P & MPW1 & BH and & B3 & Exp. \\
& & & & P86 & W91 & PW91 & HLYP & LYP & \\
\hline $\mathrm{Cl}_{2}$ & ${ }^{35} \mathrm{Cl}$ & 98.0 & 94.6 & 97.8 & 97.9 & 97.8 & 98.5 & 98.0 & 108.5 \\
$\mathrm{Br}_{2}$ & ${ }^{79} \mathrm{Br}$ & 746 & 704 & 749 & 749 & 747 & 752 & 754 & 810 \\
$\mathrm{I}_{2}$ & $127 \mathrm{I}$ & 2273 & 2122 & 2294 & 2294 & 2290 & 2298 & 2304 & 2453 \\
$\mathrm{BrCl}$ & ${ }^{79} \mathrm{Br}$ & 819 & 756 & 820 & 819 & 818 & 824 & 827 & 877 \\
& ${ }^{35} \mathrm{Cl}$ & 88.9 & 87.5 & 88.8 & 88.9 & 88.8 & 89.4 & 89.3 & 103.6 \\
$\mathrm{ClF}$ & ${ }^{35} \mathrm{Cl}$ & 122.6 & 112.5 & 117.4 & 117.4 & 117.6 & 119.7 & 117.3 & 145.9 \\
$\mathrm{IBr}$ & ${ }^{127} \mathrm{I}$ & 2568 & 2352 & 2550 & 2549 & 2547 & 2568 & 2554 & 2731 \\
& ${ }^{79} \mathrm{Br}$ & 651 & 628 & 667 & 667 & 665 & 665 & 672 & 697 \\
$\mathrm{IF}$ & ${ }^{127} \mathrm{I}$ & 3180 & 2771 & 3070 & 3067 & 3071 & 3112 & 3048 & 3438 \\
$\mathrm{ICl}$ & ${ }^{127} \mathrm{I}$ & 2786 & 2494 & 2754 & 2750 & 2750 & 2777 & 2761 & 2930 \\
& ${ }^{35} \mathrm{Cl}$ & 76 & 77 & 78 & 78 & 78 & 78 & 78 & 82.5 \\
$\mathrm{HI}$ & ${ }^{127} \mathrm{I}$ & 1739 & 1621 & 1720 & 1720 & 1710 & 1714 & 1822 & 1823 \\
\hline
\end{tabular}

Table 2. A comparison of the QCC values $(\mathrm{MHz})$ for halogen atoms calculated with the use of two different basis sets.

\begin{tabular}{lllll}
\hline Compound & Nuclei & B3LYP/6-31G* & B3LYP/3-21G* & Exp. \\
\hline $\mathrm{Cl}_{2}$ & ${ }^{35} \mathrm{Cl}$ & 104.6 & 98.0 & 108.5 \\
$\mathrm{Br}^{2}$ & ${ }^{79} \mathrm{Br}$ & 748 & 754 & 810 \\
$\mathrm{BrCl}$ & ${ }^{79} \mathrm{Br}$ & 807 & 827 & 877 \\
& ${ }^{35} \mathrm{Cl}$ & 96.2 & 89.3 & 103.6 \\
$\mathrm{ClF}$ & ${ }^{35} \mathrm{Cl}$ & 132.8 & 117.3 & 145.9 \\
$\mathrm{Cl}_{3}{ }^{-}$ & ${ }^{35} \mathrm{Cl}$ & 108.1 & 106.3 & 118 \\
$\mathrm{BrCl}_{2}{ }^{-}$ & ${ }^{79} \mathrm{Br}$ & 51.3 & 51.2 & 58 \\
${ }^{35} \mathrm{Cl}$ & 855 & 881 & - \\
$\mathrm{Br}_{3}{ }^{-}$ & ${ }^{79} \mathrm{Br}$ & 788 & 44.8 & 48 \\
$\mathrm{Br}^{-}{ }^{-}$ & ${ }^{79} \mathrm{Br}$ & 363 & 803 & 814 \\
$\mathrm{Cl}_{2}{ }^{-}$ & ${ }^{35} \mathrm{Cl}$ & 47.9 & 372 & 371 \\
\hline
\end{tabular}

The calculations were carried out with the use of 3 $21 \mathrm{G}^{*}$ (for $\mathrm{Cl}, \mathrm{Br}, \mathrm{F}$ and $\mathrm{I}$ ) atoms and 6-31 G* basis sets (for $\mathrm{Cl}$ and $\mathrm{Br}$ ), and the QCC values were obtained from the principal components of the electric field gradient tensor along the principal axes by a program written by the authors.

The materials studied were simple compounds, i. e.: halogens, interhalogen ions, and also some iodides of elements from the groups III, IV, and V of the periodic table. The relativistic effects were not taken into account.

\section{Results}

The QCC values calculated for halogen atoms with the use of various functionals, are listed in Table 1. The use of the hybrid B3LYP functional leads to the best agreement with the experimental data. The differences between the experimental and calculated QCC 


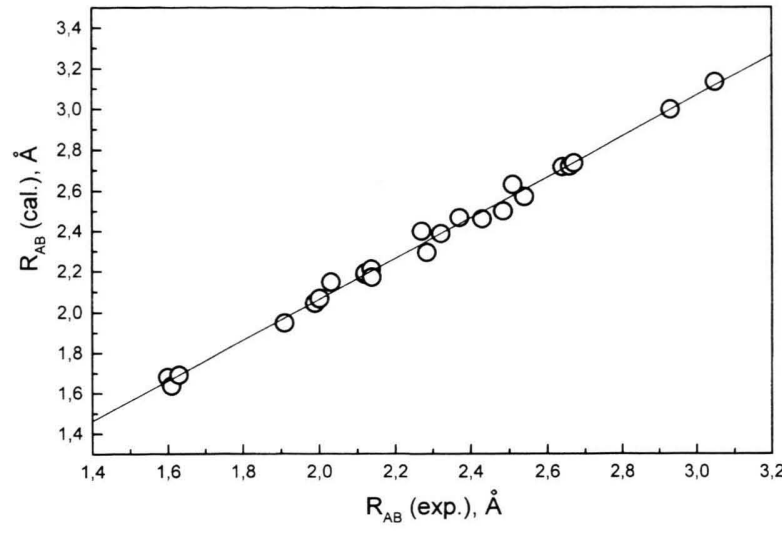

Fig. 1. The correlation between the calculated and experimental bond lengths for the compounds containing halogen atoms.

values for interhalogen molecules and ions do not depend on the halogen type.

The use of the extended basis set 6-31G* does not improve the accuracy of QCC values (Table 2). This conclusion is very important from the point of view of further applications.

A comparison of the geometrical parameters calculated by B3LYP/3-21G* for molecules and ions containing a halogen atom shows that the bond lengths have been overestimated with respect to experimental values. The correlation between the calculated and experimental bond lengths is as follows (Figure 1):

$$
\begin{aligned}
& R_{\mathrm{X}-\mathrm{Y}}^{\text {cal. }}=0,017+1,020 R_{\mathrm{X}-\mathrm{Y}}^{\text {exp. }} \\
& (r=0,998 ; s=0,03 ; n=31),
\end{aligned}
$$

where $R_{\mathrm{X}-\mathrm{X}}$ is the halogen-halogen or carbonhalogen bond length.

The factor 1,020, close to unity, confirms high quality of the results. Contrary to the X $\alpha$ method [4], the electric dipole moments $(\mu, D)$ calculated for halogen compounds are close to the experimental ones [23]:

$$
\begin{aligned}
& \mu^{\text {cal. }}=-0,10+1,22 \mu^{\text {exp. }} \\
& (r=0,998 ; s=0,2 ; n=12) .
\end{aligned}
$$

The use of the d-orbitals for heavy atoms of halogens leads to significantly better results. It is interesting to note that in the observed correlation (2) we included not only interhalogens, but also such molecules, as $\mathrm{KI}, \mathrm{CHI}_{3}, \mathrm{CH}_{2} \mathrm{I}_{2}, \mathrm{CH}_{3} \mathrm{I}$, and $\mathrm{ICl}^{\bullet} \mathrm{Py}$ complex, i.e.

\begin{tabular}{|c|c|c|c|c|c|}
\hline Comp. & Nuclei & $\begin{array}{l}e^{2} Q q_{z z}^{\text {exp. }} \\
{[\mathrm{Mz}]}\end{array}$ & $\begin{array}{l}e^{2} Q q_{z z}^{\mathrm{cal} .} \\
{[\mathrm{Mz}]}\end{array}$ & $U_{\mathrm{p}}^{\text {exp. }}$ & $U_{\mathrm{p}}^{\text {cal. }}$ \\
\hline $\mathrm{Cl}_{2}$ & ${ }^{35} \mathrm{Cl}$ & 108,5 & 98,9 & 0,989 & 0,901 \\
\hline $\mathrm{Br}_{2}^{2}$ & ${ }^{79} \mathrm{Br}$ & 810 & 750 & 1,052 & 0,974 \\
\hline $\mathrm{I}_{2}{ }^{2}$ & ${ }^{127} \mathrm{I}$ & 2453 & 2304 & 1,070 & 1,005 \\
\hline $\mathrm{F}_{2}$ & ${ }^{19} \mathrm{~F}^{*}$ & 127,2 & 98,0 & 0,978 & 0,753 \\
\hline \multirow[t]{2}{*}{$\mathrm{BrCl}$} & ${ }^{35} \mathrm{Cl}$ & 103,6 & 89,3 & 0,944 & 0,814 \\
\hline & ${ }^{79} \mathrm{Br}$ & 877 & 827 & 1,139 & 1,074 \\
\hline $\mathrm{CIF}$ & ${ }^{35} \mathrm{Cl}$ & 145,9 & 117,3 & 1,329 & 1,069 \\
\hline \multirow[t]{2}{*}{$\mathrm{IBr}^{127} \mathrm{I}$} & 2731 & 2554 & 1,191 & 1,114 & \\
\hline & ${ }^{79} \mathrm{Br}$ & 697 & 672 & 0,905 & 0,873 \\
\hline IF & ${ }^{127} \mathbf{I}$ & 3438 & 3048 & 1,499 & 1,329 \\
\hline \multirow[t]{2}{*}{$\mathrm{ICl}$} & ${ }^{127} \mathbf{I}$ & 2930 & 2761 & 1,278 & 1,204 \\
\hline & ${ }^{35} \mathrm{Cl}$ & 82,5 & 78,3 & 0,752 & 0,714 \\
\hline HI & ${ }^{127} \mathbf{I}$ & 1823 & 1822 & 0,795 & 0,794 \\
\hline HF & ${ }^{19} \mathrm{~F}^{*}$ & 40 & 58 & 0,308 & 0,446 \\
\hline $\mathrm{Cl}_{3}^{-}$ & ${ }^{35} \mathrm{Cl}$ & $118 ; 58$ & $106 ; 51$ & 1,$075 ; 0,528$ & 0,$969 ; 0,466$ \\
\hline $\mathrm{BrCl}_{2}^{-}$ & ${ }^{35} \mathrm{Cl}$ & 48 & 44,8 & 0,437 & 0,408 \\
\hline $\mathrm{Br}_{3}{ }^{2}$ & ${ }^{79} \mathrm{Br}$ & $814 ; 371$ & $803 ; 372$ & 1,$057 ; 0,482$ & 1,$043 ; 0,483$ \\
\hline \multirow{2}{*}{$\mathrm{ICl}_{2}^{-}$} & ${ }^{127} \mathrm{I}$ & $3050 ; 40$ & 2797 & 1,330 & 1,220 \\
\hline & ${ }^{35} \mathrm{Cl}$ & & 40,6 & 0,364 & 0,370 \\
\hline \multirow{2}{*}{$\mathrm{I}_{3}-$} & ${ }^{127} \mathrm{I}$ & $2478 ; 1142$ & $2448 ; 1119$ & 1,$081 ; 0,498$ & 1,$068 ; 0,488$ \\
\hline & ${ }^{35} \mathrm{Cl}$ & 45,1 & 47,2 & 0,411 & 0,430 \\
\hline $\mathrm{Cl}_{2}^{-}$ & ${ }^{35} \mathrm{Cl}$ & 54,6 & 46,4 & 0,498 & 0,423 \\
\hline $\mathrm{Br}_{2}^{2}-$ & ${ }^{79} \mathrm{Br}$ & 382 & 352 & 0,496 & 0,457 \\
\hline \multirow{2}{*}{$\mathrm{IBr}_{2}-$} & ${ }^{127} \mathbf{I}$ & 2770 & 2575 & 1,208 & 1,123 \\
\hline & ${ }^{79} \mathrm{Br}$ & 322 & 343 & 0,418 & 0,445 \\
\hline $\mathrm{CF}_{4}$ & ${ }^{19} \mathrm{~F}^{*}$ & 59,7 & 47,6 & 0,459 & 0,366 \\
\hline $\mathrm{CI}_{4}^{4}$ & ${ }^{127} \mathrm{I}$ & 2102 & 2256 & 0,917 & 0,984 \\
\hline $\mathrm{CHI}_{3}$ & ${ }^{127} \mathrm{I}$ & 2029 & 2107 & 0,885 & 0,919 \\
\hline $\mathrm{CH}_{2} \stackrel{3}{\mathrm{I}}_{2}$ & ${ }^{127} \mathbf{I}$ & 1920 & 1980 & 0,837 & 0,863 \\
\hline $\mathrm{CH}_{3} \mathrm{I}^{2}$ & ${ }^{127} \mathbf{I}$ & 1739 & 1864 & 0,758 & 0,813 \\
\hline $\mathrm{KI}$ & ${ }^{127} \mathbf{I}$ & 0 & 250 & 0 & 0,109 \\
\hline $\mathrm{BI}_{3}$ & ${ }^{127} \mathrm{I}$ & 1242 & 1209 & 0,542 & 0,527 \\
\hline $\mathrm{BF}_{3}$ & ${ }^{19} \mathrm{~F}^{*}$ & 30,2 & 25,3 & 0,232 & 0,195 \\
\hline $\mathrm{GeI}_{4}^{3}$ & ${ }^{127} \mathrm{I}$ & 1500 & 1491 & 0,654 & 0,650 \\
\hline $\mathrm{SiI}_{4}^{4}$ & ${ }^{127} \mathrm{I}$ & 1335 & 1365 & 0,582 & 0,595 \\
\hline $\mathrm{SnI}_{4}^{4}$ & ${ }^{127} \mathrm{I}$ & 1364 & 1381 & 0,595 & 0,602 \\
\hline $\mathrm{SF}_{6}^{4}$ & ${ }^{19} \mathrm{~F}^{*}$ & 60 & 46,5 & 0,461 & 0,358 \\
\hline $\mathrm{SeF}_{6}^{0}$ & ${ }^{19} \mathrm{~F}^{*}$ & 55,7 & 44,2 & 0,428 & 0,340 \\
\hline
\end{tabular}
compounds of different symmetries.
Table 3. The calculated (using B3LYP/3-21G*) and experimental QCC and $U_{\mathrm{p}}$ values for halogen atoms.

Basically, the calculations by the $\mathrm{X} \alpha$ method should provide a correlation between the calculated and experimental QCC. We have analysed results of the calculations performed with the X $\alpha$ method [4 - 6] for halogens, interhalogens and their ions. The correlation is as follows:

$$
\begin{aligned}
& U_{\mathrm{p}}^{\text {cal. }}=0,06+0,91 U_{\mathrm{p}}^{\text {exp. }} \\
& (r=0,971 ; s=0,08 ; n=26),
\end{aligned}
$$

where $U_{\mathrm{p}}=e^{2} Q q_{z z} / e^{2} Q q_{\mathrm{at}}$. is the number of unbalanced p-electrons of halogen atoms. The nuclear QCC used here were taken for ${ }^{127} \mathrm{I}: 2293 \mathrm{MHz}$; 


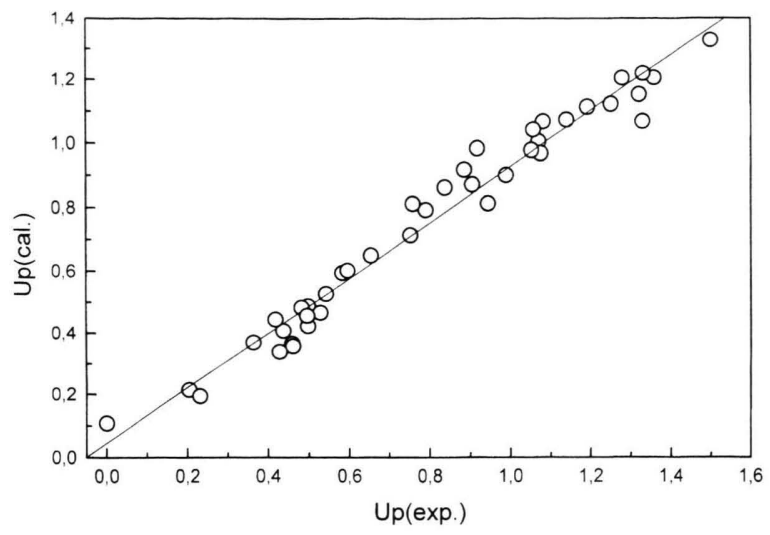

Fig. 2. The correlation between the calculated and experimental $U_{\mathrm{p}}$ values for the compounds containing halogen atoms.

${ }^{79} \mathrm{Br}: 770 \mathrm{MHz} ;{ }^{35} \mathrm{Cl}: 109,74 \mathrm{MHz},{ }^{19} \mathrm{~F}^{*}=130 \mathrm{MHz}$ $[25,26]$.

The relations (1) and (2) indicating a good agreement between calculations and experiment, have encouraged us to perform the calculations of QCC of halogen atoms and isomeric shifts for iodine compounds using the B3LYP/3-21G*. The experimental $[1,3-5,24]$ and calculated parameters obtained for quite a number of halogen compounds are given in Table 3. On the basis of these results the following correlation (more reliable then (3)) between the experimental and inferred QCC values for all halogen atoms (Figure 2), was found:

$$
\begin{aligned}
& U_{\mathrm{p}}^{\text {cal }}=0,05+0,88 U_{\mathrm{p}}^{\exp } \\
& (r=0,986 ; s=0,05 ; n=41) .
\end{aligned}
$$

The most important is that correlation (4) was obtained for all nuclei, i.e. on the basis of NQR results (on ${ }^{35} \mathrm{Cl},{ }^{79} \mathrm{Br},{ }^{127} \mathrm{I}$ nuclei) and the perturbed angular distribution method (TDPAD) [27 - 29] (on ${ }^{19} \mathrm{~F}^{*}$ nuclei). It is necessary also to note that such a correlation is valid for all compounds studied, in spite of different environment of the halogen atoms concerned.

Calculations of the isomeric shifts $(\delta)$ of iodine compounds seem very important since they can be used to infer about QCC values. The experimental $\delta$ values are known for some iodine containing compounds. It is well known that for Mössbauer atoms, such as $\mathrm{Sn}, \mathrm{Sb}$, and I, the magnitude of the isomeric shift depends simultaneously on $5 \mathrm{~s}-\left(N_{\mathrm{s}}\right)$ and $5 \mathrm{p}-$ $\left(N_{\mathrm{p}}\right)$ orbital populations of these atoms. It was shown (for example [30]), that for $\mathrm{SnCl}_{4}$ the isomer shift ${ }^{119} \mathrm{Sn}$ depends to a greater degree on the $5 \mathrm{~s}$ - than

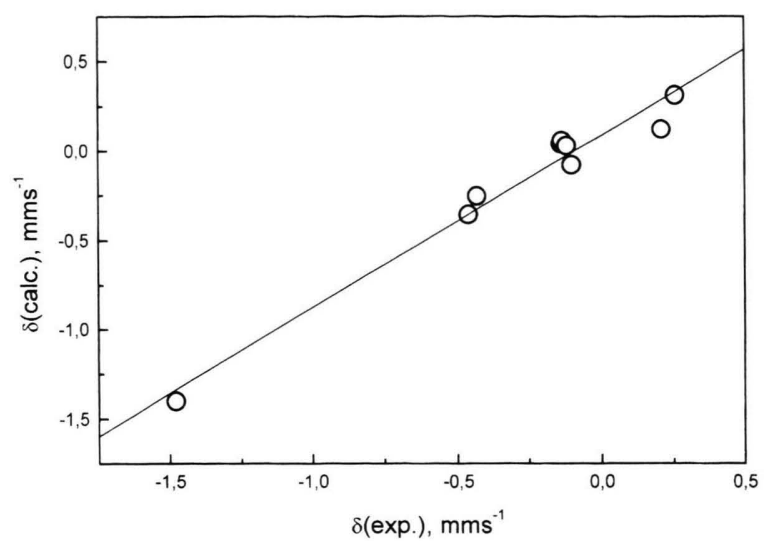

Fig. 3. The correlation between the calculated and experimental isomeric shifts for the compounds containing halogen atoms.

5p-state population. In the case of iodine compounds the following dependence between the isomeric shifts ${ }^{129} \mathrm{I}$ (rather $\mathrm{I}_{2}$ ) and the s- and p-orbital populations is observed (Figure 3):

$$
\begin{aligned}
& \delta=-10,9 N_{\mathrm{s}}-1,0 N_{\mathrm{p}}+23,3 \\
& (r=0,969 ; s=0,10 ; n=9)
\end{aligned}
$$

The experimental $[3,31]$ and calculated isomeric shifts for the following molecules $\mathrm{CI}_{4}, \mathrm{CHI}_{3}, \mathrm{CH}_{2} \mathrm{I}_{2}$, $\mathrm{CH}_{3} \mathrm{I}, \mathrm{SiI}_{4}, \mathrm{SnI}_{4}, \mathrm{KI}, \mathrm{ICl}$ and $\mathrm{IBr}$ have been compared. The obtained correlation does not seem to be very reliable (Fig. 3), probably due to a low precision of the Mössbauer experiments, but it is also possible to confirm a conclusion about the greater contribution of the $5 \mathrm{~s}$-orbital than $5 \mathrm{p}$-orbital of iodine atom to the isomeric shift. The correlation (5) is close enough to the one observed earlier for interhalogen compounds [31].

\section{Conclusions}

The DFT in the formulation as in the Gaussian 98 program, in combination with the use of the hybrid functional B3LYP (i.e. taking into account all electrons of atoms) provides very reliable QCC and Mössbauer isomeric shift values. Moreover, the use of the extended basis set $6-311 \mathrm{G}^{*}$ does not improve the QCC values significantly.

\section{Acknowledgements}

The authors wish to express gratitude to the Russian Federation Education Ministry for support of the research. 
[1] E. A. C. Lucken, Nuclear quadrupole coupling constants, Acad. Press. London 1969.

[2] C. H. Townes and B. P. Dailey, J. Chem. Phys. 17, 782 (1949).

[3] L. A. Eriksson, O. L. Malkina, V. G. Malkin, and D. R. Salahub, Int. J. Quantum Chem. 63, 575 (1997).

[4] G. A.Bowmaker and P. D. W. Boyd, J. Mol. Struct. 150, 327 (1987).

[5] G. A.Bowmaker and P. D. W. Boyd, J. Chem. Soc. Faraday Trans. 2. 83, 2211 (1987).

[6] G. A.Bowmaker, P. D. W. Boyd, and R. J. Sorrenson, J. Chem. Soc., Faraday Trans. 2. 80, 1125 (1984).

[7] P. Blaha, K. Schwarz, and P. Herzig, Phys. Rew. Lett. 54, 1192 (1985).

[8] K. Schwarz and P. Blaha, Z. Naturforsch. 47a, 197 (1992).

[9] H. Petrilli, M. Marszalek, and H. Saitovich, Z. Naturforsch. 51a, 537 (1996).

[10] A. Svane, N. E. Christensen, C. O. Rodriguez, and M. Methfessel, Phys. Rev. B. 55, 12572 (1997).

[11] H. Akai, M. Akai, S. Blugel, B. Drittler, H. Ebert, K. Terakura, R. Zeller, and P. H. Dederichs, Prog. Theor. Phys. Suppl. 101, 11 (1990).

[12] H. M. Petrilli, P. E. Blochl, P. Blaha, and K.S chwarz, Phys. Rev. B. 57, 14690 (1998).

[13] O. Kh. Poleshchuk, G. N. Dolenko, J. Koput, and J. Latosińska, Russian Coord. Chem. 23, 643 (1997).

[14] O. Kh. Poleshchuk, J. Koput, and J. Latosińska, Russian Coord. Chem., 24, 72 (1998).

[15] GAUSSIAN 98W. User's Reference. Editors E. Fritsch, M. J. Fritsch, Gaussian Inc., Pittsburgh, 1998.

[16] C. Lee, W.Yang, and R. G. Parr, Phys. Rev. B. 37, 785 (1988).
[17] J. P. Perdew, Phys. Rev. B. 33, 8822 (1986).

[18] A. D. Becke, J. Chem. Phys. 98, 5648 (1993).

[19] J. P. Perdew and Y. Wang, Phys. Rew. B. 45, 13244 (1992).

[20] L. A. Curtiss, K.Raghavachari, G. W.Trucks, and J. A. Pople, J. Chem. Phys. 94, 7221 (1991).

[21] P. J. Stephens, F. J. Devlin, C. F. Chablowski, and M. J. Frisch, J. Phys. Chem. 98, 11623 (1994).

[22] S. H. Vosko, L. Wilk, and M. Nusair, Can. J. Phys. 58, 1200 (1980).

[23] O. A. Osipov, V. I. Minkin, and A. D. Garnovskii, Spravochnik po dipolnim momentam, Viishaya Shkola, 1971.

[24] G. K. Semin, T. A. Babushkina, and G. G. Yakobson, Nuclear Quadrupole Resonance in Chemistry, John Wiley \& Sons, New York 1975.

[25] G. A. Jeffrey and T. Sakurai, Progress in Solid State Chemistry 1, 380 (1964).

[26] J. Olliges, A. Loetz, and J. Voitlander, J. Magn. Res. 69, 302 (1986).

[27] E. Bertholdt, M. Frank, F. Gubitz, W. Kreische, B. Loesch, C. H. Ott, B. Roeseler, M. Schneider, F. Schwab, K. Stammler, and G. Weeske, J. Mol. Struct. 192, 199 (1989).

[28] J. A. S. Smith, Z. Naturforsch. 41a, 453 (1986).

[29] M. Frank, F. Gubitz, W. Kreische, A. Labahn, C. Ott, B. Roseler, F. Schwab, and G. Weeske, Hyperfine Interactions. 34, 259 (1987).

[30] V. A. Varnek and A. A. Varnek, Zh. Struct. Khim. 38, 1160 (1997).

[31] Molecular Interactions, Ed. H. Ratajczak and W. J. Orville-Thomas, John Wiley \& Sons, New York 1981. 